Original Article

\title{
Characteristics and Outcomes of COVID-19 Patients with Respiratory Failure Admitted to a "Pandemic Ready" Intensive Care Unit - Lessons from Singapore
}

Si Yuan $\underline{\text { Chew }},{ }^{1}{ }_{M B B S}, M_{M C P}$, Yee Shay Lee, ${ }^{2}{ }_{M B B S, ~ M R C P}$, Deepak Ghimiray, ${ }^{2}{ }_{M B B S}$, Chee Keat $\underline{\text { Tan }},{ }^{2}$ MD, MMed (Anaes), Gerald SW Chua, ${ }^{3}$ MBBS, MRCP

\begin{abstract}
Introduction: Singapore was one of the first countries affected by the coronavirus disease 2019 (COVID-19) pandemic but has been able to prevent its healthcare system and intensive care units (ICU) from being overwhelmed. We describe the clinical features, management and outcomes of COVID-19 patients with respiratory failure admitted to our ICU. Materials and Methods: A case series of COVID-19 patients admitted to our ICU for respiratory failure from 7 February, with data censoring at 30 June 2020, was performed from a review of medical records. Results: Twenty-two COVID-19 patients were admitted to our ICU for respiratory failure. The median age was 54.5 years (IQR $30-45.5$ ), $72.7 \%$ were male and had at least one comorbidity. The Sequential Organ Failure Assessment (SOFA) and Acute Physiology and Chronic Health Evaluation (APACHE) II scores were 2.5 (IQR 1.25-7) and 10 (8.25-12) respectively. Thirteen patients required invasive mechanical ventilation (IMV) and had a median PaO2/FiO2 ratio of $194 \mathrm{mmHg}$ (IQR 173-213) after intubation. The 28-day survival was $100 \%$, with 2 patients demising subsequently. The overall ICU mortality rate was $9.1 \%$ at the time of data censoring. In IMV survivors, length of IMV and ICU stay were 11 days (IQR 9-17.75) and 16 days (IQR 12-32) respectively. Conclusion: Low COVID-19 ICU mortality was observed in our "pandemic-ready" ICU. This was achieved by having adequate surge capacity to facilitate early ICU admission and IMV, lung protective ventilation, and slow weaning. Being able to maintain clinical standards and evidence-based practices without having to resort to rationing contributed to better outcomes.
\end{abstract}

Ann Acad Med Singapore 2020;49:434-48

Key Words: Acute respiratory distress syndrome, Coronavirus, Critical care, Pandemic, Pneumonia

\section{Introduction}

An outbreak of coronavirus disease 2019 (COVID-19) was first reported in Wuhan, China on 31 December $2019^{1}$ and was soon declared a global pandemic on 11 March 2020 by the World Health Organisation (WHO). ${ }^{2}$ Although most infections are mild, initial studies from pandemic epicentres have reported a significant incidence of critical illness amongst hospitalised patients: China (17-29\%), ${ }^{3-6}$ Italy (16\%), ${ }^{7}$ and New York (14.2\%). ${ }^{8}$ Worryingly, early case series of COVID-19 patients admitted to intensive care units (ICU) suggest that many do not survive. In Wuhan, 28-day ICU mortality was reported as $61.5 \%{ }^{4}$ while case series of ICU patients with COVID-19 from New York, Seattle and Washington have reported ICU mortality rates of $22.7 \%{ }^{8} 50 \%{ }^{9}$ and $67 \%{ }^{10}$ respectively.

Despite being one of the first countries to be affected by the pandemic, COVID-19 mortality in Singapore remains low. With 26 deaths occurring

\footnotetext{
${ }^{1}$ Department of Respiratory and Critical Care Medicine, Singapore General Hospital, Singapore

${ }^{2}$ Department of Intensive Care Medicine, Ng Teng Fong General Hospital, Singapore

${ }^{3}$ Department of Medicine, Ng Teng Fong General Hospital, Singapore

Address for Correspondence: Dr Chew Si Yuan, Department of Respiratory and Critical Care Medicine, Level 3, Academia, Singapore General Hospital, Outram Rd, Singapore 169608.

Email: chewsiyuan@gmail.com
} 
in 43,881 laboratory-confirmed cases on 30 June $2020,{ }^{11}$ Singapore has a case fatality rate (CFR) of $0.059 \%$ compared to the global CFR of $4.95 \% .^{12}$ While differences in patient characteristics, availability of reliable testing and case definitions may account for the markedly lower fatality rate in Singapore, ${ }^{13}$ there is no doubt that rapid overwhelming of the healthcare systems in the pandemic epicentre of Wuhan contributed directly to higher mortality. Due to shortages of ICU equipment in Wuhan, it was estimated that only $25 \%$ of patients who died received intubation or mechanical ventilation. ${ }^{14}$ Fortunately, Singapore has been able to stay ahead of the curve thanks to early travel restrictions, social distancing measures and aggressive contact tracing and testing at the national level. ${ }^{15}$ To rapidly expand healthcare capacity, hospitals postponed non-urgent elective procedures, transferred stable patients to step-down care facilities and repurposed existing wards into isolation facilities. On 4 May 2020, the Minister of Health, Singapore updated Parliament that Singapore had 150 vacant ICU beds currently, with the ability to add a further 450 ICU beds by mid-May if required. ${ }^{16}$ At that time, Singapore had reported 22 critically ill COVID-19 patients in ICU. ICU capacity in Singapore therefore remained adequate throughout. In our single-centre case series, we describe the characteristics and outcomes of COVID-19 patients admitted to an ICU in Singapore whose capacity remains unstressed.

\section{Materials and Methods}

Ng Teng Fong General Hospital is a 700 bed hospital with a multidisciplinary medical-surgical ICU that was built 5 years ago with the facilities to manage a pandemic or mass casualty event. The ICU consists of 74 single rooms divided into 5 pods, of which only 2 pods were in full-time use prior to the pandemic. If required, each room was equipped with the space, medical gas outlets, and electrical systems on 2 pendants to accommodate 2 patients on invasive mechanical ventilation (IMV) in a surge crisis situation. It is accredited by the College of Intensive Care Medicine of Australia and New Zealand and is staffed by a department comprising specialist intensivists and non-specialist physicians. At the start of the pandemic, there were 7 full-time intensivists that provided 24-hours stay-in specialist coverage. This was increased to 13 full-time intensivists through full-time redeployment of anaesthetists, respiratory and emergency medicine physicians, who have been practising intensive care medicine on a $50 \%$ full-time equivalence basis prior to the pandemic. Non-specialist physician and nurse staffing was also augmented by re-deployment of specialists, junior physicians and nurses from the department of anaesthesia. The Acute Physiology and Chronic Health Evaluation (APACHE) II standardised mortality ratio of our ICU in 2018 was 0.77 . From the beginning, it was decided to implement segregation of ICU staffing, physical areas, and processes for usual ICU patients and COVID-19 patients to mitigate against nosocomial transmission of COVID-19. One pod of 12 negative-pressure single rooms was designated as the "pandemic ICU" dedicated to confirmed or suspect COVID-19 patients, and capacity was never exceeded. This was furnished with an adjoining shower facility for staff and 6 of these rooms were equipped with an anteroom. This pandemic ICU was staffed around the clock by a stay-in specialist intensivist supported by at least 2 junior doctors. All COVID-19 patients received at least one-to-one level of nursing.

All patients had a laboratory diagnosis of COVID-19 based on real-time reverse transcriptase-polymerase chain reaction testing on nasopharyngeal swab or endotracheal aspirate samples. Patients were admitted to our ICU if they met WHO criteria for severe pneumonia, which comprised fever or suspected respiratory infection, plus 1 of respiratory rate $>30$ breaths per minute, severe respiratory distress or oxygen saturation $<90 \%$ on room air. ${ }^{17}$ Evidence-based guidelines for acute respiratory distress syndrome $(\mathrm{ARDS})^{18}$ as well as emerging consensus statements for critical care management of COVID-19 ${ }^{19-22}$ were applied. Non-intubated oxygen-dependent patients were asked to adopt prone positioning (PP) for as long as tolerated based on protocols from small case series that have described short-term physiological improvements in oxygenation. ${ }^{23-25}$

All patients requiring IMV received lung protective ventilation with Assist Control Volume Control mode with initial tidal volume of $6 \mathrm{ml} / \mathrm{kg}$ predicted body weight (PBW). Subsequent adjustments to tidal volume, if required, were kept between $6-8 \mathrm{ml} / \mathrm{kg}$ (PBW) and care was taken to keep plateau and driving pressures below than $30 \mathrm{~cm} \mathrm{H}_{2} \mathrm{O}$ and $15 \mathrm{~cm} \mathrm{H}_{2} \mathrm{O}$ respectively. Patients with moderate severity ARDS were managed with early neuromuscular blockade and PP. Pressure support ventilation (PSV) or airway pressure release ventilation (APRV) modes were used for ventilator weaning with or without tracheostomy. Heat-moisture-exchanger (HME) filters were used to humidify inspired gases and serve as a viral filter. Water-bath heated humidifiers 
were not used due to theoretical risk of aerosol generation. All patients received thromboembolic prophylaxis with mechanical calf compressors and heparin (either subcutaneous enoxaparin 40 $\mathrm{mg}$ once daily or subcutaneous unfractionated heparin 5,000 units 3 times daily).

The de-identified clinical data of patients admitted to our intensive care unit was collected through a retrospective medical record review from 7 February 2020 to 7 June 2020. The ethics committee of National Healthcare Group (Domain Specific Review Board Reference: 2020/00704) approved this study and waived the requirement for informed consent due to the nature of retrospective medical record review. Clinical data was recorded into a datasheet with data censoring on 30 June 2020. Continuous variables were expressed as median and interquartile range (IQR) and categorical variables as frequency and percentage. No analysis for statistical significance was performed given the descriptive nature of the study.

\section{Results}

\section{Baseline Clinical Characteristics}

Twenty-six COVID-19 patients were admitted to the pandemic ICU during the study period (Fig. 1). The primary indication for ICU admission was oxygen-dependent respiratory failure in 22 patients and their demographic, baseline clinical characteristics and laboratory results are shown in Table 1. The median age was 54.5 years (IQR 51-59). Nine $(40.9 \%)$ patients were migrant workers while the rest were Singapore residents. Fifteen patients were admitted to the general ward initially and the median duration between hospitalisation and ICU admission was 4 (IQR 2.5-5) days. The median number of days from symptom onset to ICU admission and requirement for intubation was 8 (IQR 5.5-8) days and 9 (IQR 7-9) respectively. Sixteen (72.7\%) patients had at least 1 comorbidity. The most common comorbidities were hypertension $(10,45.5 \%)$ and diabetes mellitus $(7,31.8 \%)$. The median body

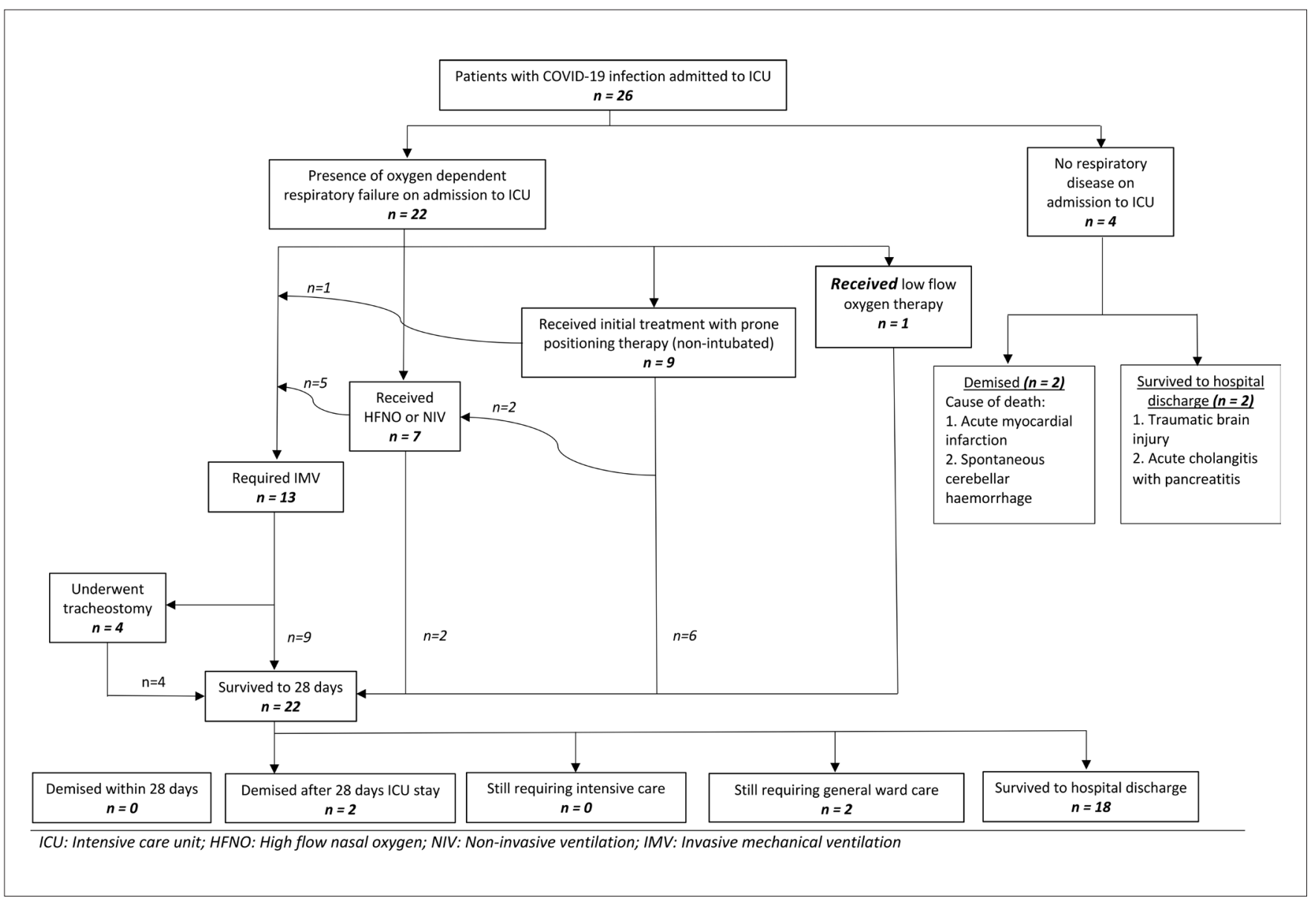

Fig.1. Indications for Admission, Initial Ventilatory Treatment and Outcomes of all COVID-19 Patients Admitted to the ICU 
Table 1. Baseline Characteristics of COVID-19 Patients with Respiratory Failure admitted to the ICU

\begin{tabular}{|c|c|c|}
\hline Demographics & $n=22$ & \\
\hline Median age (IQR) & $54.5(30-45.5)$ & \\
\hline Age $<50$ years & $7(31.8 \%)$ & \\
\hline Age $50-60$ years & $10(45.5 \%)$ & \\
\hline Age $60-70$ years & $2(9.1 \%)$ & \\
\hline Age $>70$ years & $3(13.6 \%)$ & \\
\hline Male gender & $16(72.7 \%)$ & \\
\hline \multicolumn{3}{|l|}{ Residential status and ethnicity } \\
\hline Local resident, Chinese & $8(36.3 \%)$ & \\
\hline Local resident, Malay & $5(22.7 \%)$ & \\
\hline Migrant worker & $9(40.9 \%)$ & \\
\hline Comorbidities & No. $(\%)$ of patients $(n=22)$ & \\
\hline Hypertension & $10(45.5 \%)$ & \\
\hline On ACE-I or ARB & $6(27.2 \%)$ & \\
\hline Diabetes mellitus & $7(31.8 \%)$ & \\
\hline Hyperlipidaemia on treatment with statins & $6(27.2 \%)$ & \\
\hline Chronic kidney disease & $4(18.2 \%)$ & \\
\hline Chronic lung disease & $2(9.1 \%)$ & \\
\hline Total with $\geq 1$ comorbidity & $16(72.7 \%)$ & \\
\hline BMI (IQR) & $26(23.1-32.6)^{*}$ & \\
\hline Overweight (defined as BMI $\geq 25$ ) & $3(13.6 \%)$ & \\
\hline Obesity (defined as BMI $\geq 30$ ) & $6(27.2 \%)$ & \\
\hline Clinical presentation on admission to hospital & No. $(\%)$ of patients $(n=22)$ & \\
\hline Fever & $20(90.9 \%)$ & \\
\hline Cough & $17(77.2 \%)$ & \\
\hline Dyspnoea & $4(18.1 \%)$ & \\
\hline \multicolumn{3}{|l|}{ Admission characteristics } \\
\hline Admission to general ward prior to admission to ICU & $15(68.2 \%)$ & $n=22$ \\
\hline Median time between hospital and ICU admission (days) & $4(2.5-5)$ & $n=15$ \\
\hline Median number of days from symptom onset of requirement for supplemental oxygen (IQR) & $8(5.5-8)$ & $n=22$ \\
\hline Median number of days from symptom onset to admission to ICU (IQR) & $8(5.5-9)$ & $n=22$ \\
\hline Median number of days from symptom onset to requirement for intubation (IQR) & $9(7-9)$ & $n=13$ \\
\hline Laboratory tests at time of admission to ICU, mean (range) & & Reference range \\
\hline Haemoglobin, (range) & $13.7(8.8-14.5)$ & $13.1-17.2 \mathrm{~g} / \mathrm{dL}$ \\
\hline White blood cell count, (range) & $8.32(3.96-25.95)$ & $3.37-11.03 \times 10^{9} / \mathrm{L}$ \\
\hline Presence of lymphopenia (defined as $<0.98 \times 10^{9} / \mathrm{L}$ ) & $16(72.7 \%)$ & $n=22$ \\
\hline Absolute lymphocyte count at nadir (range) & $0.76(0.06-1.28)$ & $0.86-3.88 \times 10^{9} / \mathrm{L}$ \\
\hline
\end{tabular}

ACE-I: Angiotensin converting enzyme Inhibitor; ARB: Angiotensin receptor blocker; BMI: Body mass index; ICU: Intensive care unit *No data available for 3 patients. 
Table 1. Baseline Characteristics of COVID-19 Patients with Respiratory Failure admitted to the ICU (Cont'd)

\begin{tabular}{|c|c|c|}
\hline Demographics & $n=22$ & \\
\hline Presence of thrombocytopenia & $9(40.9 \%)$ & $<172 \times 10^{9} / \mathrm{L}$ \\
\hline Urea, (range) & $7.49(2-30.7)$ & $2.8-7.6 \mathrm{mmol} / \mathrm{L}$ \\
\hline Sodium, (range) & $134(127-145)$ & $134-146 \mathrm{mmol} / \mathrm{L}$ \\
\hline Creatinine, (range) & $139(29-704)$ & $64-104 \mathrm{umol} / \mathrm{L}$ \\
\hline Total bilirubin, (range) & $13.8(2.1-65.3)$ & $4.7-23.2 \mathrm{umol} / \mathrm{L}$ \\
\hline Alkaline phosphatase, (range) & $85.4(38-186)$ & $10-34 \mathrm{U} / \mathrm{L}$ \\
\hline Alanine aminotransferase, (range) & $64.2(10-354)$ & $<55 \mathrm{U} / \mathrm{L}$ \\
\hline Aspartate aminotransferase, (range) & $102.9(17-875)$ & $10-34 \mathrm{U} / \mathrm{L}$ \\
\hline C-reactive peptide, (range) & $149.7(49-356)$ & $0.0-5.0 \mathrm{mg} / \mathrm{L}$ \\
\hline Procalcitonin, (range) $\dagger^{\dagger}$ & $2.19(0.02-14.3)$ & $<0.50 \mathrm{ng} / \mathrm{mL}$ \\
\hline Lactate dehydrogenase, (range) $\dagger$ & $536(176-1001)$ & $270-550 \mathrm{U} / \mathrm{L}$ \\
\hline Ferritin, (range) $\$$ & $1995(332-6732)^{\wedge}$ & $4.6-204 \mathrm{ng} / \mathrm{mL}$ \\
\hline Elevated high sensitivity Troponin I $>34.2 \mathrm{pg} / \mathrm{ml}$ & $1(4.5 \%)$ & $n=22$ \\
\hline Evidence of co-infection (\%) & $4(18.2 \%)$ & $n=22$ \\
\hline
\end{tabular}

ACE-I: Angiotensin converting enzyme Inhibitor; ARB: Angiotensin receptor blocker; BMI: Body mass index; ICU: Intensive care unit $\dagger$ No data available for 2 patients.

$\$$ No data available for 5 patients.

mass index (BMI) was 26 (IQR 23.1-32.6), with 3 $(13.6 \%)$ and $6(27.2 \%)$ patients meeting WHO criteria for overweight and obesity. Four patients had evidence of bacterial co-infection on microbiological culture.

Characteristics and Outcomes of Patients receiving PP (non-intubated) and High-flow Nasal Oxygen (HFNO) Therapy

Nine non-intubated patients $(40.9 \%)$ received initial treatment on ICU admission with PP for a median duration of 2 (IQR 1-4) days (Table 2). Their median values for Sequential Organ Failure Assessment (SOFA), APACHE II was 1 (IQR 1-2) and 9 (IQR 8-10) respectively. The median arterial partial pressure of oxygen $\left(\mathrm{PaO}_{2}\right)$ to fraction of inspired oxygen $\left(\mathrm{FiO}_{2}\right)$ ratio was $241 \mathrm{mmHg}$ (IQR 223-286) at baseline and $325 \mathrm{mmHg}$ after $30-180$ minutes. Patients tolerated a median duration of 10 hours of PP on day 1. Two patients eventually required IMV and 1 patient required a combination of non-invasive ventilation (NIV) and HFNO therapy (Fig.1). Seven patients received initial treatment with HFNO with 5 patients requiring IMV subsequently.

\section{Characteristics of Patients receiving IMV}

Thirteen (59\%) patients in total received IMV (Table 2). At time of intubation, the median SOFA and APACHE II scores were 7 (IQR 5-8) and 13 (IQR 10-23) respectively. The median $\mathrm{PaO}_{2} / \mathrm{FiO}_{2}$ ratio immediately after intubation was $194 \mathrm{mmHg}$ (IQR 173-213) with all patients fulfilling the Berlin criteria for ARDS of moderate severity. ${ }^{26}$ Patients on IMV received a median positive end-expiratory pressure (PEEP) of 11 (IQR 10-14) on day 1, with all patients receiving neuromuscular blockade for a median of 3 days (IQR 2-3). The mean plateau and driving pressures were $22.5 \mathrm{~cm} \mathrm{H}_{2} \mathrm{O}$ (IQR 20.5-25) and $10 \mathrm{~cm} \mathrm{H}_{2} \mathrm{O}$ (IQR 8-12) respectively on day 1 IMV. Static respiratory compliance was $29 \mathrm{ml} / \mathrm{cm} \mathrm{H}_{2} 0$ (IQR 27.5-35.4). Seven (53.8\%) patients received $\mathrm{PP}$ with before and after $\mathrm{PaO}_{2} / \mathrm{FiO}_{2}$ ratios of $127 \mathrm{mmHg}$ (IQR 127-137.5) and $201 \mathrm{mmHg}$ (IQR 170.5-238.5) respectively. One patient required extracorporeal membrane oxygenation (ECMO) therapy for 30 days and was successfully weaned from ECMO and IMV to nocturnal NIV at the time of data censoring. All patients received investigational COVID-19 therapy. Table 3 lists individualised case summaries and outcomes of patients requiring IMV 
Table 2. Clinical Course, Treatment and Outcomes of COVID-19 Patients with Respiratory Failure

\begin{tabular}{|c|c|c|}
\hline SOFA score at time of ICU admission (IQR) & $2.5(1.25-7)$ & $n=22$ \\
\hline APACHE II score at time of ICU admission (IQR) & $10(8.25-12)$ & \\
\hline Underwent non-intubated prone positioning (\%) & $9(40.9 \%)$ & \\
\hline Use of non-invasive ventilation (\%) & $1(4.5 \%)$ & \\
\hline Use of high flow nasal oxygen therapy (\%) & $7(31.8 \%)$ & \\
\hline Required invasive mechanical ventilation (\%) & $13(59.1 \%)$ & \\
\hline Required vasopressors (\%) & $13(59.1 \%)$ & \\
\hline Use of steroid therapy $(\%)$ & $5(22.7 \%)$ & \\
\hline Among 9 patients who received initial prone positioning therapy (non-intubated) & & $n=9$ \\
\hline SOFA score (IQR) & $1(1-2)$ & \\
\hline $\mathrm{PaO}_{2} / \mathrm{FiO}_{2}$ ratio (IQR) prior to prone positioning & $241(233-286)$ & \\
\hline $\mathrm{PaO}_{2} / \mathrm{FiO}_{2}$ ratio (IQR) 30-180 minutes after prone positioning & $325(254-380)$ & \\
\hline A-a gradient prior to prone positioning & $87.7(84.1-94.8)$ & \\
\hline A-a gradient 30-180 minutes after prone positioning & $72.9(56.7-84.7)$ & \\
\hline Duration of prone positioning therapy in days (IQR) & $2(1-4)$ & \\
\hline Number of hours of prone position tolerated by patient on day 1 (IQR) & $10(3-10)$ & \\
\hline Longest continuous duration of prone position tolerated in hours (IQR) & $4(3-7)$ & \\
\hline Required invasive mechanical ventilation (\%) & $2(22.2 \%)$ & \\
\hline Survival at 28 days from ICU admission & $8(88.9 \%)$ & \\
\hline Survivors discharged from hospital, median hospital length of stay, days (IQR) & $18(14-19)$ & $n=7$ \\
\hline Among patients requiring invasive mechanical ventilation & $13(59.1 \%)$ & $n=13$ \\
\hline Intubation performed in the Emergency Department & $2(15.4 \%)$ & \\
\hline Intubation performed in ICU & $11(84.6 \%)$ & \\
\hline SOFA score at time of initiation of IMV (IQR) & $7(5-8)$ & \\
\hline APACHE II score at time of initiation of IMV (IQR) & $13(10-23)$ & \\
\hline \multicolumn{3}{|l|}{$\mathrm{PaO}_{2} / \mathrm{FiO}_{2}$ ratio (IQR) } \\
\hline Immediately after intubation ( $\mathrm{mmHg}$ ) & $194(173-213)$ & \\
\hline Nadir (mmHg) & $136(125-141.5)^{*}$ & \\
\hline A-a oxygen gradient after intubation & $179.9(167.5-209.2)$ & \\
\hline $\begin{array}{l}\text { Median level of positive end-expiratory positive pressure on day } \\
1 \text { invasive mechanical ventilation, } \mathrm{cm}_{2} \mathrm{O} \text { (IQR) }\end{array}$ & $11(10-14)$ & \\
\hline
\end{tabular}

A-a gradient: Alveolar-arterial gradient; APACHE II: Acute physiology and chronic health evaluation II; DVT: Deep vein thrombosis; FiO $_{2}$ : Fraction of

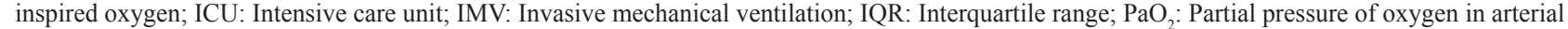
blood; PE: Pulmonary embolism; SOFA: Sequential organ failure assessment

$\dagger$ Excluding 1 patient who is currently still dependent on nocturnal non-invasive ventilation

${ }^{1}$ Defined by criteria from the Kidney Disease Improving Global Outcomes and the International Society of Nephrology.

${ }^{2}$ Defined as an alanine aminotransferase or aspartate aminotransferase level greater than 3 times the upper limit of normal. 
Table 2. Clinical Course, Treatment and Outcomes of COVID-19 Patients with Respiratory Failure (Cont'd)

Highest median fraction of inspired oxygen requirement on day $\quad 45 \%(40-52.5 \%)$

1 invasive mechanical ventilation, (range)

Highest level of positive end-expiratory positive pressure applied

$14(14-16)$

during invasive mechanical ventilation, $\mathrm{cm} \mathrm{H}_{2} \mathrm{O}$ (IQR)

Plateau pressure on day 1 invasive mechanical ventilation, $\mathrm{cm} \mathrm{H}_{2} \mathrm{O}$ (IQR)

$22.5(20.5-25)$

Driving pressure on day 1 invasive mechanical ventilation, $\mathrm{cm}_{2} \mathrm{O}$ (IQR)

$10(8-12)$

Static respiratory compliance on day 1 of invasive mechanical ventilation, $\mathrm{ml} / \mathrm{cm}$ of water (IQR)

Use of neuromuscular blockade (\%)

$13(100 \%)$

Median number of days neuromuscular blockade (IQR)

$3(2-3)$

Use of prone positioning (\%)

$\mathrm{PaO}_{2} / \mathrm{FiO}_{2}$ ratio prior to prone therapy

$127(121-137.5)$

$\mathrm{PaO}_{2} / \mathrm{FiO}_{2}$ ratio after prone therapy

$201(170.5-238.5)$

After first session of prone therapy

A-a gradient prior to prone therapy

$183(170.5-226.5)$

A-a gradient after prone therapy

$151(101-204)$

After first session of prone therapy

Absolute increase in $\mathrm{PaO}_{2}$ after prone positioning $(\mathrm{mmHg})$

$15.1(11.4-38.4)$

After first session of prone therapy

Use of extra-corporeal membrane oxygenation

$1(7.7 \%)$

Underwent tracheostomy

$4(30.8 \%)$

Presence of complications in patients on IMV

$n=13$

Pneumothorax (\%)

$1(7.7 \%)$

Ventilator associated pneumonia (\%)

$5(38.5 \%)$

Median days from intubation to onset

5 days

Acute kidney injury ${ }^{1}$

$9(69.2 \%)$

Required renal replacement therapy

$7(53.8 \%)$

Airway complications requiring re-intubation

$3(23.1 \%)$

Endotracheal tube obstruction by secretions

$2(15.4 \%)$

Endotracheal tube cuff leak

$1(7.7 \%)$

Deranged liver function tests ${ }^{2}$

$6(46.2 \%)$

Acute cardiac injury / cardiomyopathy

$1(7.7 \%)$

Venous thromboembolism (DVT or PE)

$2(15.4 \%)$

COVID-19 related encephalopathy

$1(7.7 \%)$

\section{Investigational anti-viral therapy administered}

Lopinavir/ritonavir

$7(53.8 \%)$

A-a gradient: Alveolar-arterial gradient; APACHE II: Acute physiology and chronic health evaluation II; DVT: Deep vein thrombosis; FiO 2 : Fraction of inspired oxygen; ICU: Intensive care unit; IMV: Invasive mechanical ventilation; IQR: Interquartile range; $\mathrm{PaO}_{2}$ : Partial pressure of oxygen in arterial

blood; PE: Pulmonary embolism; SOFA: Sequential organ failure assessment

$\dagger$ Excluding 1 patient who is currently still dependent on nocturnal non-invasive ventilation

${ }^{1}$ Defined by criteria from the Kidney Disease Improving Global Outcomes and the International Society of Nephrology.

${ }^{2}$ Defined as an alanine aminotransferase or aspartate aminotransferase level greater than 3 times the upper limit of normal. 
Table 2. Clinical Course, Treatment and Outcomes of COVID-19 Patients with Respiratory Failure (Cont'd)

\begin{tabular}{|c|c|c|}
\hline Beta-interferon & $3(23.1 \%)$ & \\
\hline Hydroxychloroquine & $3(23.1 \%)$ & \\
\hline Tocilizumab & $3(23.1 \%)$ & \\
\hline Convalescent plasma & $2(15.4 \%)$ & \\
\hline \multicolumn{3}{|l|}{ Outcomes of patients requiring IMV } \\
\hline Survival at 28 days from ICU admission & $13(100 \%)$ & $\begin{array}{l}\qquad n=13 \\
1 \text { patient demised on day } 30 \text { of ICU } \\
\text { stay and } 1 \text { patient demised on day } \\
31 \text { of ICU stay }\end{array}$ \\
\hline Remains dependent on mechanical ventilation & $1(7.7 \%)$ & $n=13$ \\
\hline Re-intubation rate & $3(23.1 \%)$ & $n=13$ \\
\hline $\begin{array}{l}\text { Survivors extubated from invasive mechanical ventilation (IMV), } \\
\text { Median duration of IMV in days (IQR) }\end{array}$ & $11(9-17.75)$ & $n=10 \dagger$ \\
\hline Survivors discharged from ICU, median ICU length of stay, days (IQR) & $16(12-32)$ & $n=11$ \\
\hline Survivors discharged from hospital, length of hospitalisation in days (IQR) & $40(32-50)$ & $n=9$ \\
\hline
\end{tabular}

A-a gradient: Alveolar-arterial gradient; APACHE II: Acute physiology and chronic health evaluation II; DVT: Deep vein thrombosis; $\mathrm{FiO}_{2}$ : Fraction of

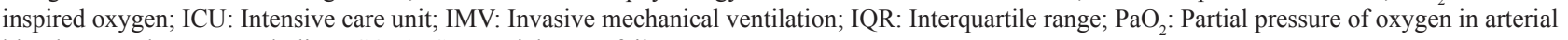
blood; PE: Pulmonary embolism; SOFA: Sequential organ failure assessment

$\dagger$ Excluding 1 patient who is currently still dependent on nocturnal non-invasive ventilation

${ }^{1}$ Defined by criteria from the Kidney Disease Improving Global Outcomes and the International Society of Nephrology.

${ }^{2}$ Defined as an alanine aminotransferase or aspartate aminotransferase level greater than 3 times the upper limit of normal.

\section{Patient Outcomes}

All 22 patients with respiratory failure survived to 28 days from ICU admission. At time of data censoring, 2 patients (Table 3-Patients 8 and 11) demised on ICU day 30 and 31 respectively, 2 patients continue to require general ward care and 18 patients survived to hospital discharge. The median duration of IMV and ICU stay in survivors was 11 days (IQR 9-17.75) and 16 days (IQR 12-32). Four patients required tracheostomy for prolonged IMV. Nine patients developed acute kidney injury with seven patients requiring haemodialysis. Five patients developed ventilator associated pneumonia and 2 patients developed sudden endotracheal tube obstruction by secretions requiring emergency re-intubation. All patients received venous thromboembolic (VTE) prophylaxis with heparin and did not develop VTE during their ICU stay. However, 2 patients who did not require IMV subsequently developed VTE during convalescence in general ward. One patient was still on heparin prophylaxis when he was diagnosed with pulmonary embolism 15 days after ICU admission. In the second patient, heparin prophylaxis was discontinued 2 days prior to the diagnosis of pulmonary embolism 12 days after ICU admission.

\section{Discussion}

In our single centre case series, all 22 COVID-19 patients admitted to our ICU for respiratory failure survived to 28 days, although 2 patients subsequently demised, giving an overall ICU mortality rate of $9.1 \%$. ICU mortality of 13 patients requiring IMV was $15.4 \%$. This is in marked contrast from reported ICU mortality rates from large case series from various countries: China $49 \%,{ }^{27}$ Lombardy, Italy, $26 \%,{ }^{28}$ United Kingdom 43.2\%, ${ }^{29}$ Scotland 38\%, ${ }^{30}$ Atlanta, Georgia, United States, $30.9 \%{ }^{31}$

Various reasons could account for the significant differences in ICU outcomes. Firstly, at the time of reporting, many patients remain admitted in the ICU$58 \%$ of patients in the Lombardy cohort ${ }^{28}$ and $56.1 \%$ of patients in the New York case series. ${ }^{8}$ Attempts to measure mortality at the early phase of the pandemic based on a smaller group of patients with completed outcomes with a short duration of follow-up could 


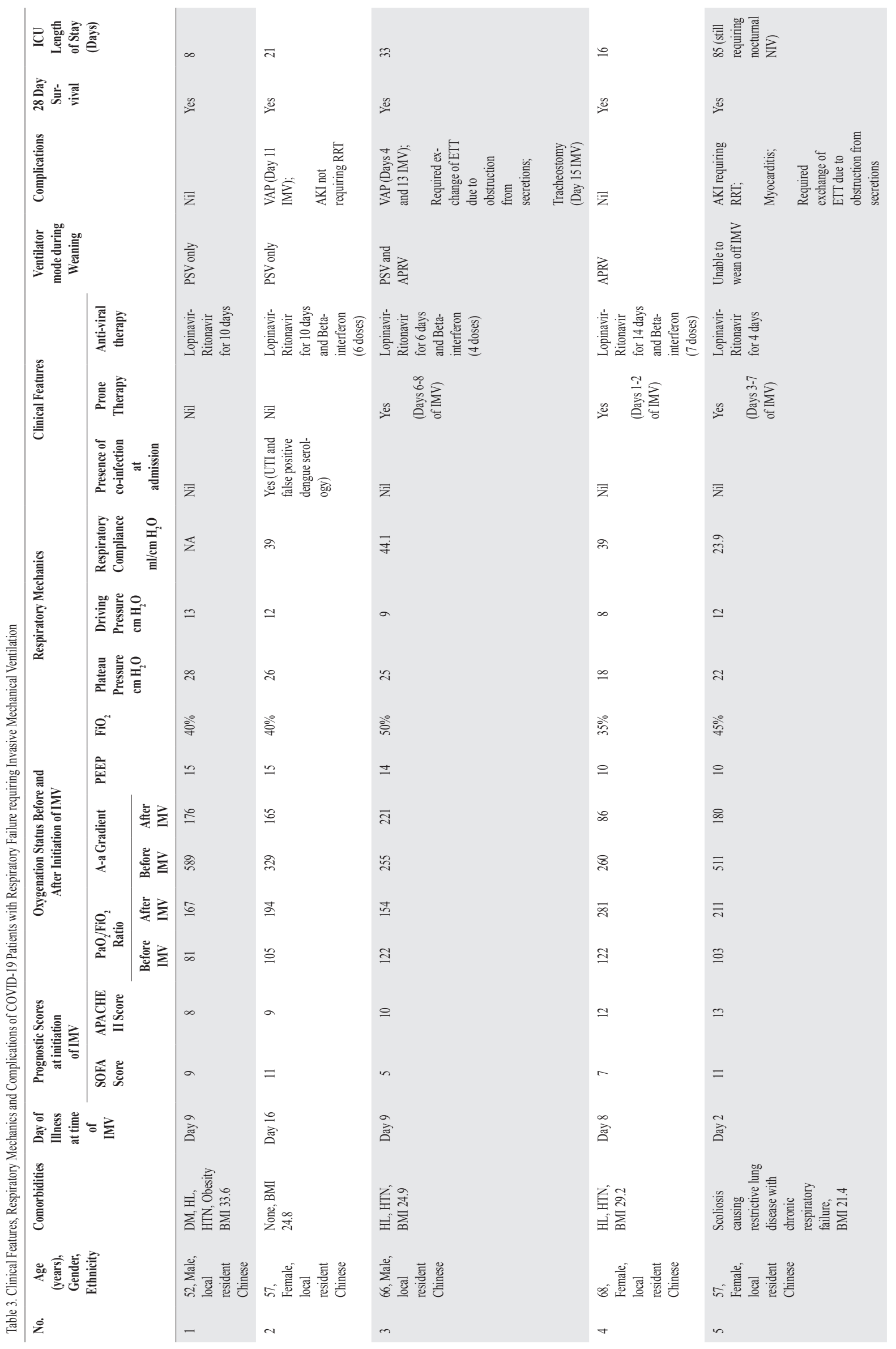




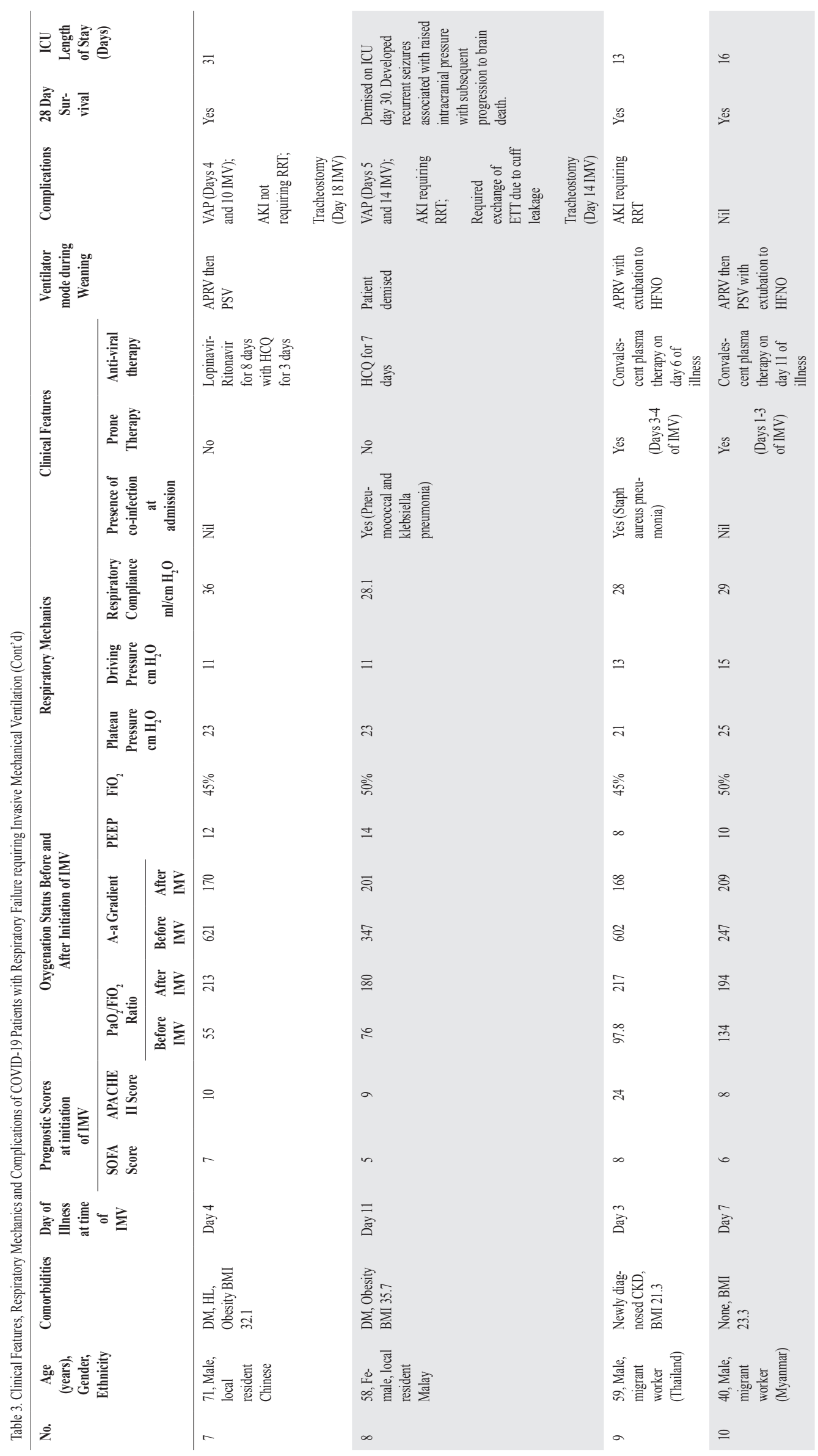




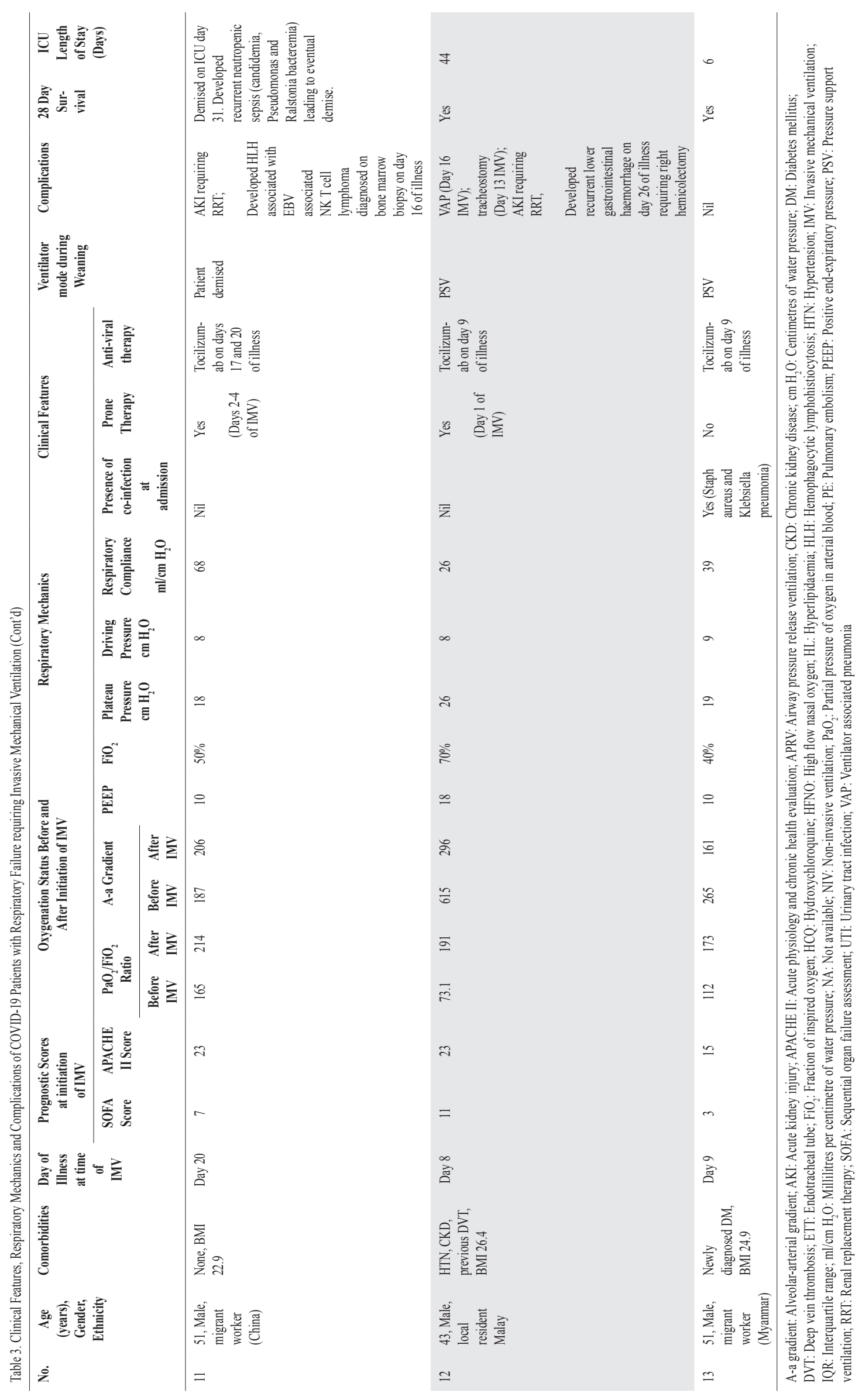


skew statistical interpretation in favour of higher mortality rates. In a more recent systematic review of 15 studies, it was found that the pooled ICU mortality rate was $25.7 \%,{ }^{32}$ which is not higher than the typical $35-45 \%$ mortality rate of ARDS.

Secondly, our patients had a lower risk profile for severe disease compared to data available from various large case series (Table 4). This may be related to differences in criteria for ICU admission. We applied the WHO criteria for severe pneumonia for ICU admission, while ICUs in overwhelmed healthcare systems might have applied more stringent admission criteria as part of rationing. Our patients were younger with a median age of 54.5 years compared to the median ages of 63 years in the Lombardy cohort, and 60 years in the Intensive Care National Audit and Research Centre (ICNARC) report for the United Kingdom. ${ }^{29}$ Our patients also had lower ICU prognostication scores at ICU admission compared to other cohorts. Our overall median SOFA and APACHE II score on admission to ICU was 2.5 (IQR 1.25-7) and 10 (IQR 8.23-12) respectively. This is in contrast to the median APACHE II score of 17

(IQR 14-19) in a Wuhan cohort, ${ }^{4}$ the median APACHE II score of 14 (IQR 11-18) in the ICNARC report, ${ }^{29}$ the median APACHE II score of 15 in the Scottish Intensive Care Society Audit Group
(SICSAG) report ${ }^{30}$ and the median SOFA score of 7 (IQR 5-11) for the Atlanta cohort. ${ }^{31}$ Finally, the severity of ARDS in our patients was milder compared to the other patient cohorts. The median $\mathrm{PaO}_{2} / \mathrm{FiO}_{2}$ ratio of our patients who required IMV was 194 (IQR 173-213) while patients from Lombardy, ${ }^{28}$ the United Kingdom ${ }^{29}$ and Atlanta ${ }^{31}$ had lower $\mathrm{PaO}_{2} / \mathrm{FiO}_{2}$ ratios of 160 (IQR 114-220), 118.5 (IQR 84.8-165) and 132 (IQR 100-178) respectively. The lower risk profile of our patients could be attributed to the high proportion of migrant workers $(40 \%)$ in our case series. This reflected the nature of the pandemic in Singapore, which disproportionately affected thousands of migrant workers who lived in crowded dormitories. ${ }^{33}$ Migrant workers in Singapore comprise largely of young men who have little or no medical comorbidities, and are predominantly employed in the construction industry. Finally, higher body mass index (BMI) has been associated with more severe COVID-19 disease ${ }^{34}$ and our patients had a lower median BMI of 26 compared to the median BMI of 30 (IQR 26-35) in the Atlanta cohort. ${ }^{34}$

Thirdly, our ICU capacity was never overwhelmed at any stage of the pandemic and did not have to practice rationing of ICU resources. There was therefore no pressure on our intensivists to perform

Table 4. Comparison of Admission Characteristics and Outcomes of COVID-19 Patients Admitted to the ICU

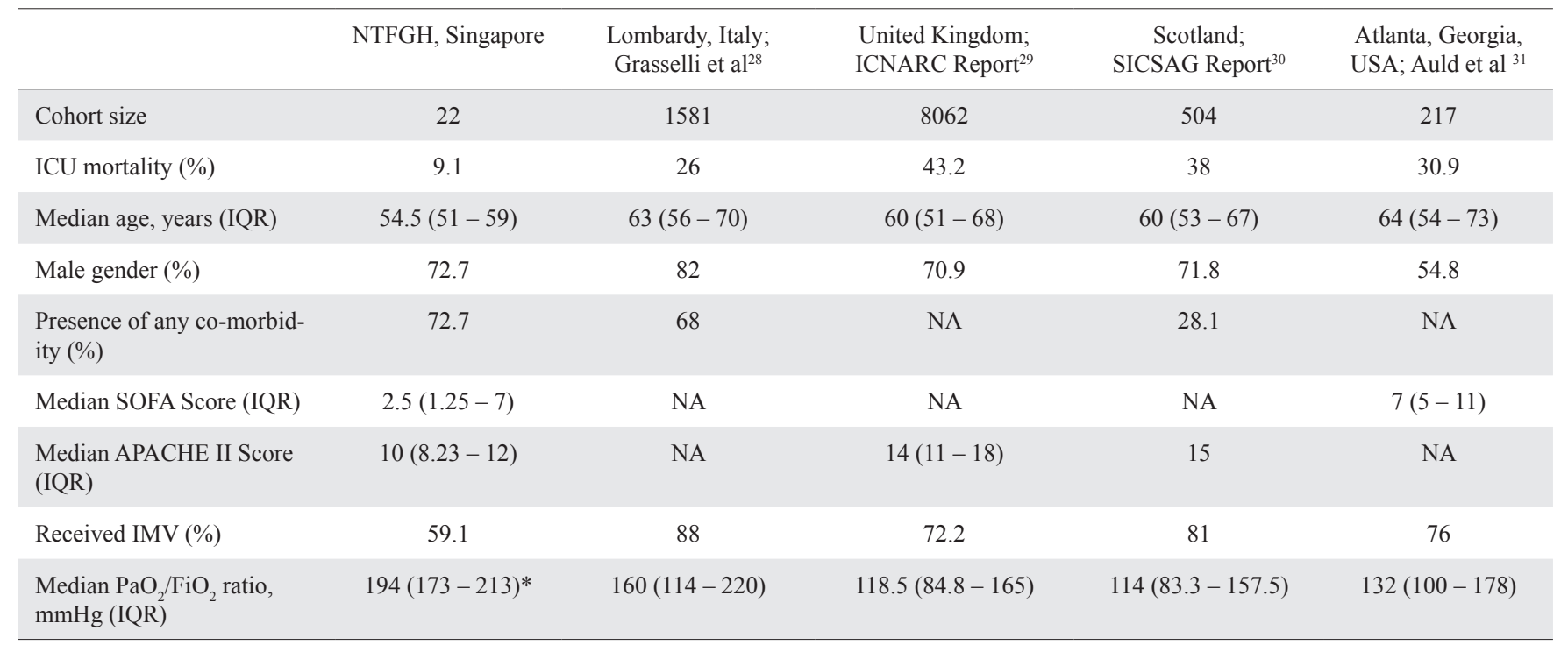

APACHE II: Acute physiology and chronic health evaluation; $\mathrm{FiO}_{2}$ : Fraction of inspired oxygen; IQR: Interquartile range; NA: Not available; NTFGH: $\mathrm{Ng}$ Teng Fong General Hospital; $\mathrm{PaO}_{2}$ : Partial pressure of oxygen in arterial blood; SOFA: Sequential organ failure assessment.

*For patients who received invasive mechanical ventilation. 
high-risk extubations on our patients to free up ICU beds and ventilators. To date, the highest occupancy rate of our pandemic ICU was seven out of thirteen beds. In a case series of 109 COVID-19 decedents in Wuhan, ${ }^{35}$ all of whom required critical care, it was reported that only $46.8 \%$ patients were eventually admitted to ICU due to resource constraints. Ventilators were also in short supply as evidenced by only $64.7 \%$ of ICU patients receiving IMV. Similarly, in Scotland, it was reported that the baseline capacity for the highest level of complex ICU care was exceeded from 31 March to 24 April 2020, with peak activity exceeding the baseline by $46 \% .^{30}$ Due to a lack of ventilators, HFNO and NIV therapy was widely applied, typically outside the ICU, in overwhelmed healthcare systems such as Wuhan, ${ }^{36,37}$ and Italy. ${ }^{38}$ This was despite a lack of evidence on their benefits and potentially might have led to delays in intubation.

None of our patients in our case series demised without having been on IMV. HFNO and NIV were also only attempted in the ICU, as opposed to the general ward or high dependency setting. Patients in our case series were either intubated in the emergency department on presentation to the hospital, or intubated in the ICU with no emergent intubations in the general ward setting (Table 2). This was achieved by early referral of deteriorating patients to the ICU. Based on early descriptions of rapid development of ARDS from the onset of dyspnoea, ${ }^{5}$ our intensivists practiced a low threshold to admit patients with risk factors of advanced age and medical comorbidities who developed hypoxemia requiring supplemental oxygen for monitoring and early IMV, if required. This was reflected in a high proportion of patients (40.9\%) who did not require IMV in our case series. This is in comparison to the higher incidence of IMV in the case series of Lombardy $88 \%,{ }^{28}$ United Kingdom $72.2 \%,{ }^{29}$ Scotland $81 \%,{ }^{30}$ and Atlanta $76 \%{ }^{31}$ This practice of early ICU outreach and admission has been shown to be associated with lower mortality in Jiangsu province, China $^{39}$ and may have similarly contributed to a lower mortality rate in our patients.

Having sufficient ICU staff was also instrumental in ensuring that all patients received standard ICU care in line with evidence-based guidelines for ARDS and COVID-19. Prone positioning, a labour-intensive intervention, was also applied to more than half of IMV patients and this could not have been done if there was insufficient ICU manpower. Based on small studies conducted outside the ICU, ${ }^{25,40,41}$ we had also practised PP on 9 hypoxemic non-intubated patients in the ICU, in case worsening respiratory failure was masked by the short-term improvements in oxygenation, and thus managed to avoid IMV for seven patients. To date, no healthcare worker (HCW) in Singapore contracted COVID-19 in the course of work ${ }^{42}$ due to adequate provision of personal protective equipment and segregation of healthcare for non-COVID-19 and COVID-19 patients. Inadequate protection of $\mathrm{HCW}$ can significantly widen the health capacity and demand gap by draining hospital staffing and increasing demand for healthcare. In a case series from Wuhan, it was reported that $29 \%$ of hospitalised COVID-19 patients were healthcare workers (including 2 from the ICU) who contracted the infection at work. ${ }^{3}$

\section{Study Strengths and Limitations}

The major strength of our study is the finding of low COVID-19 mortality with good standard supportive care in the ICU which comprises timely admission, early intubation, lung protective ventilation strategies and careful weaning from IMV. A case series from Hong Kong - a city which enjoyed early success in pandemic mitigation-reported a comparably low ICU mortality rate of $12.5 \%{ }^{43}$ and underscores the importance of forward planning for ICUs to have sufficient surge capacity in the event of a pandemic. Just like Hong Kong, Singapore has been fortunate to have drawn lessons from its experience with the Severe Acute Respiratory Syndrome and was able to rapidly implement pandemic preparedness drawer plans for its ICUs. ${ }^{44-46}$ Our "pandemic ready" ICU was able to achieve mortality rates that were lower than patients with other causes of $\mathrm{ARDS}^{47}$ by having adequate surge capacity, in turn allowing clinical standards and evidence-based practices to be maintained without resorting to disaster rationing.

Our study is however limited by the small sample size and single-centre experience and therefore the findings may not be generalisable to other patients with severe COVID-19. Secondly, due to data censoring on 30 June 2020, the long-term outcomes of our patients who remain hospitalised are unknown. Thirdly, some patients had missing laboratory tests or missing clinical data.

\section{Conclusion}

Our study describes the characteristics and outcomes of COVID-19 patients admitted to a "pandemic ready" ICU in Singapore whilst capacity remains unstressed. Low ICU mortality rates can be achieved with good 
accessibility to ICU, early intubation, lung protective ventilatory strategies and good general supportive care in the ICU even if effective anti-viral therapies are not yet widely available. The morbidity of severe COVID-19, however, remains considerable and can rapidly deplete ICU resources in a pandemic. A "pandemic ready" ICU is able to maintain clinical standards and continue evidence-based practices without having to resort to rationing of resources, thereby keeping mortality rates low in the early phase of a pandemic.

\section{REFERENCES}

1. World Health Organization. Novel coronavirus - China, 12 January 2020. Available at: http://www.who.int/csr/don/12-january-2020-novelcoronavirus-china/en/. Accessed on 1 July 2020.

2. World Health Organization. WHO Director-General's opening remarks at the media briefing on COVID-19, 11 March 2020. Available at: https://www.who.int/dg/speeches/detail/who-director-general-sopening-remarks-at-the-media-briefing-on-covid-19---11-march-2020. Accessed on 30 March 2020.

3. Wang $\mathrm{D}, \mathrm{Hu} \mathrm{B}, \mathrm{Hu} \mathrm{C}$, Zhu F, Liu X, Zhang J, et al. Clinical characteristics of 138 hospitalized patients with 2019 novel coronavirus-infected pneumonia in Wuhan, China. JAMA 2020;323:1061-69.

4. Yang X, Yu Y, Xu J, Shu H, J 'an X, Liu H, et al. Clinical course and outcomes of critically ill patients with SARS-CoV-2 pneumonia in Wuhan, China: a single-centered, retrospective, observational study. Lancet Respir Med 2020;8:475-81.

5. Huang C, Wang Y, Li X, Ren L, Zhao J, Hu Y, et al. Clinical features of patients infected with 2019 novel coronavirus in Wuhan, China. Lancet 2020;395:497-506.

6. Chen N, Zhou M, Dong X, Qu J, Gong F, Han Y, et al. Epidemiological and clinical characteristics of 99 cases of 2019 novel coronavirus pneumonia in Wuhan, China: a descriptive study. Lancet 2020;395:507-13.

7. Grasselli G, Pesenti A, Cecconi M. Critical care utilization for the COVID-19 outbreak in Lombardy, Italy: Early experience and forecast during an emergency response. JAMA 2020;323:1545-46.

8. Richardson S, Hirsch JS, Narasimhan M, Crawford JM, McGinn T, Davidson KW, et al. Presenting characteristics, comorbidities, and outcomes among 5700 patients hospitalized with COVID-19 in the New York City area. JAMA. 2020;323:2052-59.

9. Bhatraju PK, Ghassemieh BJ, Nichols M, Kim R, Jerome KR, Nalla AK, et al. Covid-19 in critically ill patients in the Seattle region - case series. N Engl J Med 2020;382:2012-22.

10. Arentz M, Yim E, Klaff L, Lokhandwala S, Riedo FX, Chong M, et al. Characteristics and outcomes of 21 critically ill patients with COVID-19 in Washington state. JAMA 2020;323:1612-14.

11. Ministry of Health, Singapore. Updates on COVID-19 (Coronavirus Disease 2019) local situation. Available at: https://www.moh.gov.sg/ covid-19. Accessed on 1 July 2020.

12. World Health Organisation. WHO Coronavirus disease (COVID-19), situation report-162, 30 June 2020. Available at: https://www.who. int/docs/default-source/coronaviruse/20200630-covid-19-sitrep-162. pdf?sfvrsn=e00a5466_2. Accessed 1 July 2020.
13. Koh D, Cunningham AC. Counting Coronavirus disease 2019 (COVID-19) cases: Case definitions, screened populations and testing techniques matter. Ann Acad Med Singapore 2020;49:161-65.

14. Xie J, Tong Z, Guan X, Du B, Qiu H, Slutsky AS. Critical care crisis and some recommendations during the COVID-19 epidemic in China. Intensive Care Med 2020;46:837-40.

15. Ministry of Health, Singapore. Ministerial statement by Minister Lawrence Wong on update on whole-of-government response to COVID-19, 25 Mar 2020. Available at: https://www.mnd.gov.sg/ newsroom/parliament-matters/speeches/view/ministerial-statementby-minister-lawrence-wong-on-update-on-whole-of-governmentresponse-to-covid-19. Accessed on 1 July 2020.

16. Ministry of Health, Singapore. Ministerial statement by Mr Gan Kim Yong, Minister for Health, at Parliament, on the second update on whole-of-government response to COVID-19, 4 May 2020. Available at: https://www.moh.gov.sg/news-highlights/ details/ministerial-statement-by-mr-gan-kim-yong-minister-for-healthat-parliament-on-the-second-update-on-whole-of-government-responseto-covid-19-4-may-2020. Accessed on 1 July 2020.

17. World Health Organization. Clinical management of severe acute respiratory infection when novel coronavirus $(\mathrm{nCoV})$ infection is suspected: interim guidance, 25 January 2020. Available at: https:// apps.who.int/iris/handle/10665/330854. Accessed on 1 July 2020.

18. Fan E, Del Sorbo L, Goligher EC, Hodgson CL, Munshi L, Walkey AJ, et al. An official American Thoracic Society/European Society of Intensive Care Medicine/Society of Critical Care Medicine clinical practice guideline: mechanical ventilation in adult patients with acute respiratory distress syndrome. Am J Respir Crit Care Med 2017; 195:1253-63.

19. Murthy S, Gomersall CD, Fowler RA. Care for critically ill patients With COVID-19. JAMA 2020;323:1499-1500.

20. Wilson KC, Chotirmall SH, Bai C, Rello J, American Thoracic Society-led International Task Force. COVID-19: Interim guidance on management pending empirical evidence, 2020 Apr 3. Available: at https://www.thoracic.org/professionals/clinical-resources/diseaserelated-resources/covid-19-guidance.pdf. Accessed on 1 July 2020.

21. Bouadma L, Lescure FX, Lucet JC, Yazdanpanah Y, Timsit JF. Severe SARS-CoV-2 infections: practical considerations and management strategy for intensivists. Intensive Care Med 2020;46:579-82.

22. Phua J, Weng L, Ling L, Egi M, Lim CM, Divatia JV, et al. Intensive care management of coronavirus disease 2019 (COVID-19): challenges and recommendations. Lancet Respir Med 2020;8:506-17.

23. Caputo ND, Strayer RJ, Levitan R. Early Self-proning in awake, non-intubated patients in the emergency department: A single ED's experience during the COVID-19 pandemic. Acad Emerg Med 2020;27:375-78.

24. Sztajnbok J, Maselli-Schoueri JH, Cunha de Resende Brasil LM, Farias de Sousa L, Cordeiro CM, Sansão Borges LM, et al. Prone positioning to improve oxygenation and relieve respiratory symptoms in awake, spontaneously breathing non-intubated patients with COVID-19 pneumonia. Version 2. Respir Med Case Rep 2020;30:101096.

25. Elharrar X, Trigui Y, Dols AM, Touchon F, Martinez S, Prud' homme $\mathrm{E}$, et al. Use of prone positioning in nonintubated patients with COVID-19 and hypoxemic acute respiratory failure. JAMA 2020;323:2336-38.

26. ARDS Definition Task Force, Ranieri VM, Rubenfeld GD, Thompson BT, Ferguson ND, Caldwell E, et al. Acute respiratory distress syndrome: the Berlin Definition. JAMA 2012;307:2526-33. 
27. Wu Z, McGoogan JM. Characteristics of and important lessons from the coronavirus disease 2019 (COVID-19) outbreak in China: summary of a report of 72314 cases from the Chinese Center for Disease Control and Prevention. JAMA 2020;323:1239-42.

28. Grasselli G, Zangrillo A, Zanella A, Antonelli M, Cabrini L, Castelli A, et al. Baseline characteristics and outcomes of 1591 patients infected with SARS-CoV-2 admitted to ICUs of the Lombardy region, Italy. JAMA 2020;323:1574-81.

29. ICNARC report on COVID-19 in critical care 29 May 2020. Available at: https://www.icnarc.org/DataServices/Attachments/ Download/8419d345-c7a1-ea11-9126-00505601089b. Accessed on 1 July 2020.

30. Scottish Intensive Care Society Audit Group report on COVID-19, 20 June 2020. Available at: https://beta.isdscotland.org/findpublications-and-data/population-health/covid-19/scottish-intensivecare-society-audit-group-report-on-covid-19/. Accessed on 1 July 2020

31. Auld SC, Caridi-Scheible M, Blum JM, Robichaux C, Kraft C, Jacob JT, et al. ICU and ventilator mortality among critically ill adults with coronavirus disease 2019. Crit Care Med 2020; DOI: 10.1097/CCM.0000000000004457.

32. Quah P, Li A, Phua J. Mortality rates of patients with COVID-19 in the intensive care unit: a systematic review of the emerging literature. Crit Care 2020;24:285.

33. Singapore Government Agency. Containing COVID-19 spread at foreign worker dormitories. Available at: https://www.gov.sg/article/ containing-covid-19-spread-at-foreign-worker-dormitories. Accessed on 6 June 2020 .

34. Ong SWX, Young BE, Leo YS, Lye DC. Association of higher body mass index (BMI) with severe coronavirus disease 2019 (COVID-19) in younger patients. Clin Infect Dis 2020; DOI: 10.1093/ cid/ciaa 548

35. Du RH, Liu LM, Yin W, Wang W, Guan LL, Yuan ML, et al. Hospitalization and critical care of 109 decedents with COVID-19 pneumonia in Wuhan, China. Ann Am Thorac Soc 2020;17:839-46.

36. Guan WJ, Ni ZY, Hu Y, Liang WH, Ou CQ, He JX, et al. Clinical characteristics of coronavirus disease 2019 in China. N Engl J Med 2020;382:1708-20.
37. Wang Y, Lu X, Chen H, Chen T, Su N, Huang F, et al. Clinical course and outcomes of 344 intensive care patients with COVID-19. Am J Respir Crit Care Med 2020;201:1430-34.

38. Rosenbaum L. Facing Covid-19 in Italy - Ethics, logistics, and therapeutics on the epidemic's front line. N Engl J Med 2020; 382:1873-75.

39. Sun Q, Qiu H, Huang M, Yang Y. Lower mortality of COVID-19 by early recognition and intervention: experience from Jiangsu Province. Ann Intensive Care 2020;10:33.

40. Jiang LG, LeBaron J, Bodnar D, Caputo ND, Chang BP, Chiricolo $\mathrm{G}$, et al. Conscious proning: An introduction of a proning protocol for nonintubated, awake, hypoxic emergency department COVID-19 patients. Acad Emerg Med 2020;27:566-69.

41. Sartini C, Tresoldi M, Scarpellini P, Tettamanti A, Carcò F, Landoni G, et al. Respiratory parameters in patients with COVID-19 after using noninvasive ventilation in the prone position outside the intensive care unit. JAMA 2020;323:2338-40.

42. Kurohi R. 66 healthcare workers infected but none likely in the course of work. The Straits Times, 5 May 2020 Available at: https://www.straitstimes.com/politics/66-healthcare-workers-infectedbut-none-likely-in-the-course-of-work. Accessed on 1 July 2020.

43. Ling L, So C, Shum HP, Chan PKS, Lai CKC, Kandamby DH, et al. Critically ill patients with COVID-19 in Hong Kong: a multicentre retrospective observational cohort study. Crit Care Resusc 2020; Epub 6 April 2020.

44. Liew MF, Siow WT, MacLaren G, See KC. Preparing for COVID-19: early experience from an intensive care unit in Singapore. Crit Care 2020;24:83.

45. Lee CCM, Thampi S, Lewin B, Lim TJD, Rippin B, Wong WH, et al. Battling COVID-19: Critical care and peri-operative healthcare resource management strategies in a tertiary academic medical centre in Singapore. Anaesthesia 2020;75:861-71.

46. Goh KJ, Wong J, Tien JC, Ng SY, Duu Wen S, Phua GC, et al. Preparing your intensive care unit for the COVID-19 pandemic: practical considerations and strategies. Crit Care 2020;24:215.

47. Erickson SE, Martin GS, Davis JL, Matthay MA, Eisner MD; NIH NHLBI ARDS Network. Recent trends in acute lung injury mortality: 1996-2005. Crit Care Med 2009;37:1574-79. 